\title{
Electronic Structure and Spectroscopy of Cadmium Thiolate Clusters
}

\author{
Hui-Jean Liu,* Joseph T. Hupp, and Mark A. Ratner* \\ Department of Chemistry and Materials Research Center, Northwestern University, \\ Evanston, Illinois 60208-3113
}

Received: February 12, 1996; In Final Form: April 30, 1996 ${ }^{\otimes}$

\begin{abstract}
The singly excited configuration interaction (CIS) approximation and the CNDO model Hamiltonian have been employed to calculate the optical spectra of $\left[\mathrm{Cd}(\mathrm{SPh})_{4}\right]^{2-},\left[\mathrm{Cd}_{2}(\mathrm{SPh})_{6}\right]^{2-}$, and $\left[\mathrm{Cd}_{4}(\mathrm{SPh})_{10}\right]^{2-}$ and the artificial defect models $\left[\mathrm{Cd}_{2}(\mathrm{SPh})_{5}\right]^{-}$and $\left[\mathrm{Cd}_{4}(\mathrm{SPh})_{9}\right]^{-}(\mathrm{Ph}=$ phenyl). The electronic transitions have been characterized by evaluating changes in orbital electron population between ground and excited states; this allows clear assignment of the nature of the optical transitions. The simulated spectra are able to reproduce well the main features of experimental optical transition bands. The lowest energy bands for the first three compounds are due to both intraligand and ligand-to-metal charge transfer transitions. The terminal thiolate levels lie insignificantly higher in energy than the bridging ones. Both experimental and simulated spectra show a blue shift with increasing sizes, directly opposed to simple predictions based on quantum confinement. This can be explained by the Jahn-Teller effect. Incomplete capping of a $\mathrm{Cd}$ atom creates a low-lying state that acts as an electron trap in an optical transition. Transitions involving this state have small oscillator strengths and produce a long tail on the red side of the spectrum. Analysis of changes in electron population shows that these red tails can be attributed to charge transfer transitions from the thiolates to the defect $\mathrm{Cd}$, and thus significant dipole moment changes result. The self-consistent reaction field model has also been used to study the effects of solvent on optical spectra; no important changes in calculated spectra are obtained.
\end{abstract}

\section{Introduction}

There has been extensive study, both experimentally and theoretically, on how a semiconductor nanocrystal evolves to a bulk material and how its corresponding electronic properties change. ${ }^{1}$ Experimental observations show a close relationship between the size of nanocrystals, the lowest energy optical absorption peak, and the highest energy band of the luminescence spectrum. $^{2}$ These are usually assigned to the transition between the valence band and the conduction band or, in the molecular analogy, between HOMO and LUMO. Among the significant issues are the size-dependent shift of the lowest energy transition and its oscillator strength, ${ }^{3}$ the geometry of nanocrystals and its effect on the electronic structure, ${ }^{2 c, 3,4}$ and the location of electron-hole pairs in real space. ${ }^{5,6}$

Recent photoluminescence experiments suggest strong resonance mixing between surface and core states. ${ }^{4 \mathrm{a}}$ Also, it is wellknown that surface states arise from loss of periodicity at crystal surfaces. ${ }^{4 \mathrm{~b}, 5,38}$ These observations raise questions concerning electron and hole locations, possible preferred sites in the excited state, energetic position of surface states (caused by dangling bonds/incomplete capping on the surface), and their possible mixing with other states. If an electron-hole pair is separated spatially in the excited state, then a change in electron population from ground to excited state will be observed, i.e. a significant dipole moment change. Therefore, by creating an incomplete capping site on the cluster surface and analyzing the change in electron population, we can further understand these issues.

Theoretical models such as the effective mass model, ${ }^{2 \mathrm{~d}, 7-9}$ the tight-binding model, ${ }^{10}$ the time-dependent tight-binding approach, ${ }^{11}$ and the empirical pseudopotential method ${ }^{12}$ have been employed to understand the electronic properties of nanocrystals.

The effective mass model seems adequate for larger particles but overestimates the band gap for smaller ones; it considers a

\footnotetext{
${ }^{\otimes}$ Abstract published in Advance ACS Abstracts, July 1, 1996.
}

nanocrystal as a particle in a spherically symmetric well with an infinite wall on the particle surface. Recently, one group modified the effective mass model by taking account of the valence band degeneracy and the conduction band nonparabolicity. ${ }^{2 \mathrm{~d}}$ Results are in good agreement with experiment for rather large particles. ${ }^{2 \mathrm{~d}}$ However, the surface localization of electron and/or hole has been ignored by imposing a boundary condition such that both the electron and hole wave functions vanish at the particle surface.

The empirical pseudopotential method ${ }^{12}$ yields better agreement with experiment. This model describes the nanoparticle as a bulk material, allowing the use of the periodic boundary conditions (or introducing the reciprocal lattice vector $G$ ). The particle interface is taken as an infinite wall. Recent work modifies the form factors of both zinc-blende and hexagonal structures to reproduce the bulk crystal field splitting at the top of the valence band. ${ }^{13}$ However, the problem of surface effects is still not addressed.

The band gap energies calculated by the tight-binding scheme $^{10}$ and the time-dependent tight-binding approach ${ }^{11}$ are also in reasonable agreement with experiment for intermediate to larger particles. For the latter approach, ${ }^{11}$ surface effects have been considered by covering the surface with dangling bonds and reparametrizing the interactions between surface atoms and ligand atoms. The electron-electron repulsion is included within the electron-hole interaction. However, the Huckeltype Hamiltonian, parametrization from the bulk band structure, and consideration of only nearest neighbor interactions make it difficult for these models to predict the band gap over a broad size range.

The semiempirical methods of electronic structure calculation have been widely employed by researchers in many areas to understand the electronic properties of molecules. ${ }^{14,16 \mathrm{~b}}$ Such calculations are able to describe efficiently, intuitively, and quite accurately the electronic properties of ground and excited states. Our goal here is to understand the nature of the electronic 
transitions for CdS nanoclusters, the generation of an optically excited electron in a cluster, the effects of a defect site on the cluster surface, and the effects of solvation on absorption spectra by using the complete neglect of differential overlap (CNDO) model Hamiltonian and the configuration interaction singles (CIS) approximation. For comparison with CNDO CIS results, the extended Huckel method (EHT) has also been used to calculate the orbital energies. Existing crystal data are used to determine the geometries. Due to limitations of computer resources and parameter availiability, only $\mathrm{CdS}$ molecules/ clusters of three sizes are examined here.

In section II, we summarize the models and analyze parameters used. Section III discusses, in order, the orbital energies from both EHT and CNDO calculations, the simulated optical spectra and assignment of the lowest energy band, the effects of a defect site located at one $\mathrm{Cd}$ atom, and the effects of solvation. Section IV gives some conclusions.

\section{Computational Details}

A. Hamiltonians and States. Two semiempirical models are employed here: the one-electron extended Huckel model $(E H T)^{15}$ and the complete neglect of differential overlap (CNDO) model, which includes electronic repulsions. ${ }^{16}$ The resonance integral, $H_{i j}$, in the EHT calculation is evaluated via the Wolfsberg-Helmholz equation ${ }^{17}$ with $K$ equal to 1.75 . To compute experimental spectra more accurately, the CNDO model with monoexcited CI or CIS has been employed. ${ }^{18}$ The computational tool is the CNDO routine in the ZINDO program of Zerner and co-workers. ${ }^{19}$ The matrix elements of the Fock operator are ${ }^{16}$

$$
\begin{gathered}
F_{\mu \mu}=U_{\mu \mu}+\left(P_{\mathrm{AA}}-(1 / 2) P_{\mu \mu}\right) \gamma_{\mathrm{AA}}+\sum_{\mathrm{B}(\neq \mathrm{A})}\left(P_{\mathrm{BB}} \gamma_{\mathrm{AA}}-V_{\mathrm{AB}}\right) \\
F_{\mu \nu}=\beta_{\mathrm{AB}}^{\circ} S_{\mu \nu}-(1 / 2) P_{\mu \nu} \gamma_{\mathrm{AB}} \quad \mu \neq v
\end{gathered}
$$

The atomic matrix elements of the one-electron Hamiltonian $U_{\mu \mu}$ are determined from the corresponding ionization potential. The one-center two-electron Coulomb integral $\gamma_{\mathrm{AA}}$ has three different values, $\gamma_{\mathrm{AA}}^{\mathrm{ss}}, \gamma_{\mathrm{AA}}^{\mathrm{dd}}$, and $\gamma_{\mathrm{AA}}$, for transition metal $\mathrm{Cd}^{20}$ and only one value for others. For the optical spectra, the Mataga-Nishimoto formula is employed to evaluate the twocenter two-electron integrals $\gamma_{\mathrm{AB}}$ (including $\gamma_{\mathrm{AB}}^{\mathrm{ss}}, \gamma_{\mathrm{AB}}^{\mathrm{dd}}$, and $\left.\gamma_{\mathrm{AB}}^{\mathrm{sd}}\right):^{21}$

$$
\begin{aligned}
& \gamma_{\mathrm{AB}}=\frac{1}{a+R_{\mathrm{AB}}} \\
& a=\frac{2}{\gamma_{\mathrm{AA}}+\gamma_{\mathrm{BB}}}
\end{aligned}
$$

The bonding parameter $\beta_{\mathrm{AB}}^{\circ}$ in eq 2 is calculated also by the Wolfsberg-Helmholz approximation with appropriate interaction factors parametrized for $\sigma$ and $\pi$ bonds. ${ }^{22} V_{\mathrm{AB}}$ and $S_{\mu \nu}$ are calculated as described in ref $16 \mathrm{~b}$.

The lowest transition energies and oscillator strengths are calculated using CIS, including less than 700 singly excited configurations of valence orbitals. To assure that the number of singly excited configurations is large enough to converge, tests have been done on the calculated transition energies as a function of the number of configurations at 211.3, 201.8, and $223.6 \mathrm{~nm}$ for $\left[\mathrm{Cd}(\mathrm{SPh})_{4}\right]^{2-}([\mathbf{C d 1}]),\left[\mathrm{Cd}_{2}(\mathrm{SPh})_{6}\right]^{2-}([\mathbf{C d} 2])$, and $\left[\mathrm{Cd}_{4}(\mathrm{SPh})_{10}\right]^{2-}([\mathbf{C d} 4])$, respectively. Results show that enough configurations are included: transition energies are unchanged to within $100 \mathrm{~cm}^{-1}$ or so (Appendix A). The state dipole

\section{SCHEME 1}
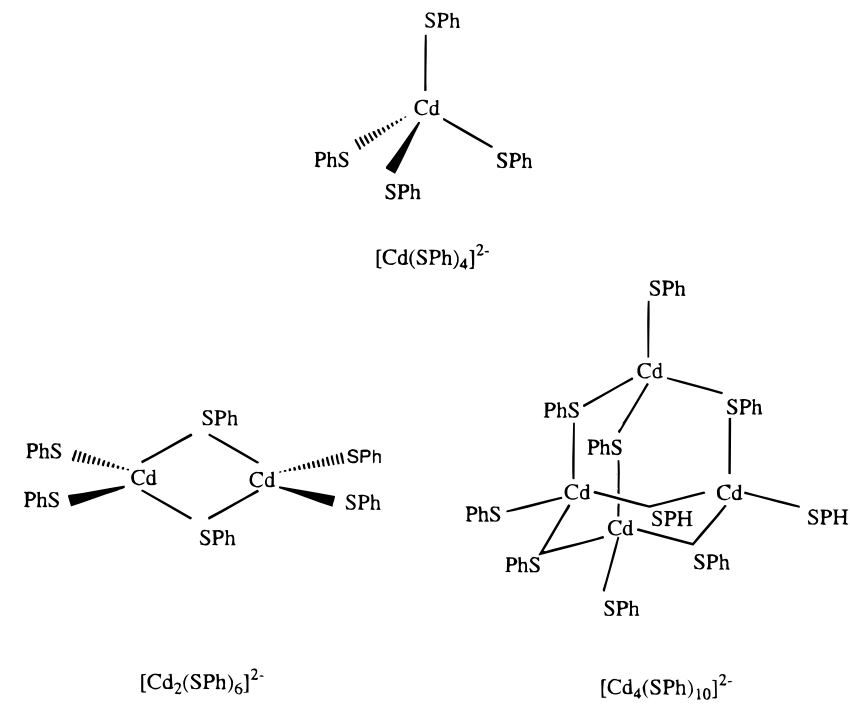

moments are evaluated as expectation values of the dipole moment operator. For the elements $\mathrm{C}, \mathrm{H}$, and $\mathrm{S}$, the default parameters are employed without further refinement to fit the experimental data (Appendix B). For Cd the Slater-Condon $F^{\circ}\left(\gamma_{\mathrm{AA}}\right)$ integral is taken from ref 23. The geometries of [Cd1], [Cd2], and [Cd4] used in both EHT and CNDO calculations are from crystal structure determinations (Scheme 1). ${ }^{24-26}$ Experimental optical absorption spectra are from the literature. $^{25,27}$

B. Line Shapes. CIS calculation results give discrete transition energies and oscillator strengths, while an experimental absorption spectrum yields a curve of the wavelengthdependent extinction coefficient function. To compare the calculated spectrum with empirical bands and also to take account of the Franck-Condon broadening, it is convenient to use the Loretzian line shape to simulate each calculated electronic transition. ${ }^{28}$ The normalized Lorentzian line shape with extinction coefficient function, $\epsilon^{\prime}(v)$, centered at $v_{0}$, can be expressed as

$$
\frac{2}{\Gamma} \epsilon^{\prime}(v)=\frac{\epsilon_{\max }}{\pi\left(\nu-v_{0}\right)^{2}+(\Gamma / 2)^{2}}
$$

where $\epsilon_{\max }$ is the extinction coefficient at the band maximum, $v_{0}$, and $\Gamma$ is the bandwidth at half-maximum (fwhm). The oscillator strength for this band is

$$
f\left(v_{0}\right)=k \int \epsilon^{\prime}(v) \mathrm{d} v
$$

where $k$ is a constant equal ${ }^{28,29}$ to $4.33 \times 10^{-9} \mathrm{M} \mathrm{cm}^{2}$.

The integral on the right-hand side of eq 6 , called the integrated extinction coefficient, extends over the entire band. To correlate $f$ with $\epsilon_{\max }$, the Lorentzian line shape function (eq 5) can be fed into eq 6 :

$$
f\left(v_{0}\right)=k \int_{-\infty}^{\infty} \epsilon^{\prime}(v) \mathrm{d} v=k \epsilon_{\max }
$$

or

$$
\epsilon_{\max }=\frac{f\left(v_{0}\right)}{k}
$$

Replacement of $\epsilon_{\max }$ in eq 5 with eq 8 yields 


$$
\begin{aligned}
\epsilon_{v_{0}}^{\prime}(v) & =\frac{1}{k_{\left(v-v_{0}\right)^{2}+(\Gamma / 2)^{2}}} \\
& =1.155 \times 10^{8} \frac{f\left(v_{0}\right) \Gamma}{\left(v-v_{0}\right)^{2}+(\Gamma / 2)^{2}}
\end{aligned}
$$

$\epsilon^{\prime} v_{0}(v)$, in units of $\mathrm{M}^{-1} \mathrm{~cm}^{-1}$, denotes the molar extinction coefficient $^{28}$ associated with the transition occurring at wavenumber $v_{0}$. Since there are transitions at various energies, the calculated spectra are obtained by superposition of each $\epsilon^{\prime}{ }_{v_{0}}(v)$ band:

$$
\begin{aligned}
\epsilon(v) & =\sum \epsilon_{v_{0}}^{\prime} \\
& =\sum_{v_{0}} 1.155 \times 10^{8} \frac{f\left(v_{0}\right) \Gamma}{\left(v-v_{0}\right)^{2}+(\Gamma / 2)^{2}}
\end{aligned}
$$

$\epsilon(v)$ is the simulated spectrum used to compare with the experimental one. $\Gamma$ is adjusted to fit the experimental data.

C. Electron Populations. Electron density plots are generally pictorially inadequate to show how electron density changes during an excitation process for unsymmetrical molecules such as [Cd1], [Cd2], and [Cd4]. Therefore, estimation of the changes in electron population for each element from ground to excited state is needed to understand the nature of each transition. We can introduce a very approximate way to evaluate the changes in population. Assume that an electron in the $\mu$ th molecular orbital of a compound in the ground state is excited to the $v$ th virtual orbital. Then the total change in the total number of electrons, assuming zero differential overlap, is

$$
\begin{aligned}
0 & =\Delta n=n^{\mathrm{ex}}-n^{\mathrm{g}} \\
& =\sum_{\mathrm{A}} \sum_{i}^{\mathrm{AO}} \sum_{\sigma}^{\mathrm{occ}} c_{i \sigma \mathrm{A}}^{\mathrm{ex} *} c_{i \sigma \mathrm{A}}^{\mathrm{ex}}-\sum_{\mathrm{A}} \sum_{j}^{\mathrm{AO}} \sum_{\gamma}^{\mathrm{occ}} c_{j \gamma \mathrm{A}}^{\mathrm{g}^{*}} c_{j \gamma \mathrm{A}}^{\mathrm{g}}
\end{aligned}
$$

Here A, $\sigma$, and $i$ label atoms, molecular orbitals, and atomic orbitals, respectively. For a single excitation, common occupations cancel, and therefore

$$
0=\Delta n=\sum_{\mathrm{A}} \sum_{i}^{\mathrm{AO}}\left(c_{i v \mathrm{~A}}^{\mathrm{ex}^{*}} c_{i v \mathrm{~A}}^{\mathrm{ex}}-c_{i \mu \mathrm{A}}^{\mathrm{g}^{*}} c_{i \mu \mathrm{A}}^{\mathrm{g}}\right)
$$

All terms cancel except those MO's involved in the electronic transition $\mu \rightarrow \nu$. Since each excited state consists of several singly excited configurations, the resulting total change in Mulliken population is obtained by appropriately weighted contributions from all of the participating configurations.

$$
\begin{aligned}
& 0=\Delta N=N^{\mathrm{ex}}-N^{\mathrm{g}} \\
& =\sum_{\mathrm{A}} \sum_{\mathrm{k}(\mu \rightarrow v)}^{\text {config }} d_{\mathrm{k}}^{*} d_{\mathrm{k}} \sum_{i}^{\mathrm{AO}}\left(c_{i v \mathrm{Ak}}^{\mathrm{ex} *} c_{i v \mathrm{Ak}}^{\mathrm{ex}}-c_{i \mu \mathrm{Ak}}^{\mathrm{g}^{*}} c_{i \mu \mathrm{Ak}}^{\mathrm{g}}\right)
\end{aligned}
$$

$d_{\mathrm{k}}^{*} d_{\mathrm{k}}$ is the probability for configuration $\mathrm{k}$ to occur and is determined in CIS calculations. Here only those configurations with $\left|d_{\mathrm{k}}\right|$ greater than 0.1 are considered. Therefore for element A, the change in Mulliken population from the ground state to an excited state can be expressed as

$$
\Delta N_{\mathrm{A}}=\sum_{\mathrm{k}(\mu \rightarrow v)}^{\text {config }} \sum_{i}^{\mathrm{AO}} d_{\mathrm{k}}^{*} d_{\mathrm{k}}\left(c_{i v \mathrm{Ak}}^{\mathrm{ex} *} c_{i v \mathrm{Ak}}^{\mathrm{ex}}-c_{i \mu \mathrm{Ak}}^{\mathrm{g}^{*}} c_{i \mu \mathrm{Ak}}^{\mathrm{g}}\right)
$$

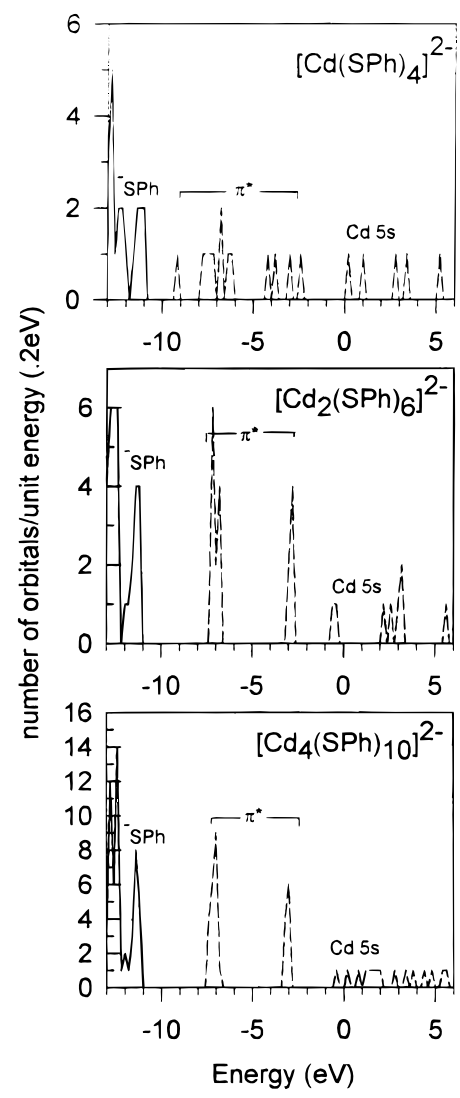

Figure 1. Orbital energies in EHT calculations for $\left[\mathrm{Cd}(\mathrm{SPh})_{4}\right]^{2-}$ (top), $\left[\mathrm{Cd}_{2}(\mathrm{SPh})_{6}\right]^{2-}$ (middle), and $\left[\mathrm{Cd}_{4}(\mathrm{SPh})_{10}\right]^{2-}$ (bottom). The solid lines represent occupied molecular orbitals. The dashed lines are from virtual orbitals.

$\Delta N_{\mathrm{A}}$ has a value between 0 and 1 . Thus $\Delta N_{\mathrm{A}} \times 100 \%$ represents the percentage of one electron that is gained by atom A during an excitation process.

D. Solvent Effects. The effect of solvent is examined by applying the self-consistent reaction field (SCRF) method. ${ }^{30}$ To exclude the volume of counterions, the size of the solute molecules is evaluated through the solute volume density obtained from crystal data.

E. Defects. The effects on electronic spectra due to incomplete capping of the cluster surface are explored by removing one terminal ligand from the studied molecule. All defect molecules retain the same geometries, and no surface reconstruction is considered.

\section{Results and Discussion}

A. Frontier Orbitals of CdS Molecules. For bulk $\mathrm{CdS}$ semiconductor materials, the frontier orbitals consist of $\mathrm{S}$ atoms as the valence band and $\mathrm{Cd}$ atoms as the conduction band. On the other hand, for molecular-sized CdS compounds, the loss of periodicity or variations in the coordinating environment cause different redox properties for the same kind of atoms in a molecule. That results in removal of degeneracy occurring in both $\mathrm{Cd}$ and $\mathrm{S}$ bands, and therefore different bands of optical transitions arise. For example, $[\mathbf{C d 2}]$ and $[\mathbf{C d 4}]$ clusters contain both bridging and capping thiolate ligands: The $\mathrm{S}$ atom of a bridging thiolate has two neighboring $\mathrm{Cd}$ atoms, but the $\mathrm{S}$ atom of a terminal thiolate shares its electrons with only one $\mathrm{Cd}$ atom. Thus the terminal sulfur is anticipated to be more electrondonating than the bridging one. Both EHT and CNDO calculations show that, even though the terminal and bridging sulfurs have distinct redox properties and the terminal sulfurs 


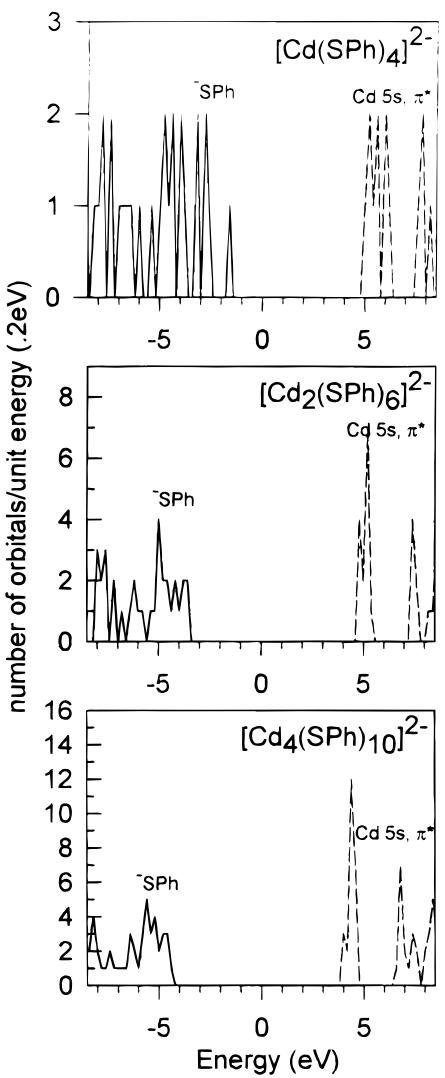

Figure 2. Orbital energies in $\mathrm{CNDO}$ calculations for $\left[\mathrm{Cd}(\mathrm{SPh})_{4}\right]^{2-}$ (top), $\left[\mathrm{Cd}_{2}(\mathrm{SPh})_{6}\right]^{2-}$ (middle), and $\left[\mathrm{Cd}_{4}(\mathrm{SPh})_{10}\right]^{2-}$ (bottom). Layout as in Figure 1.
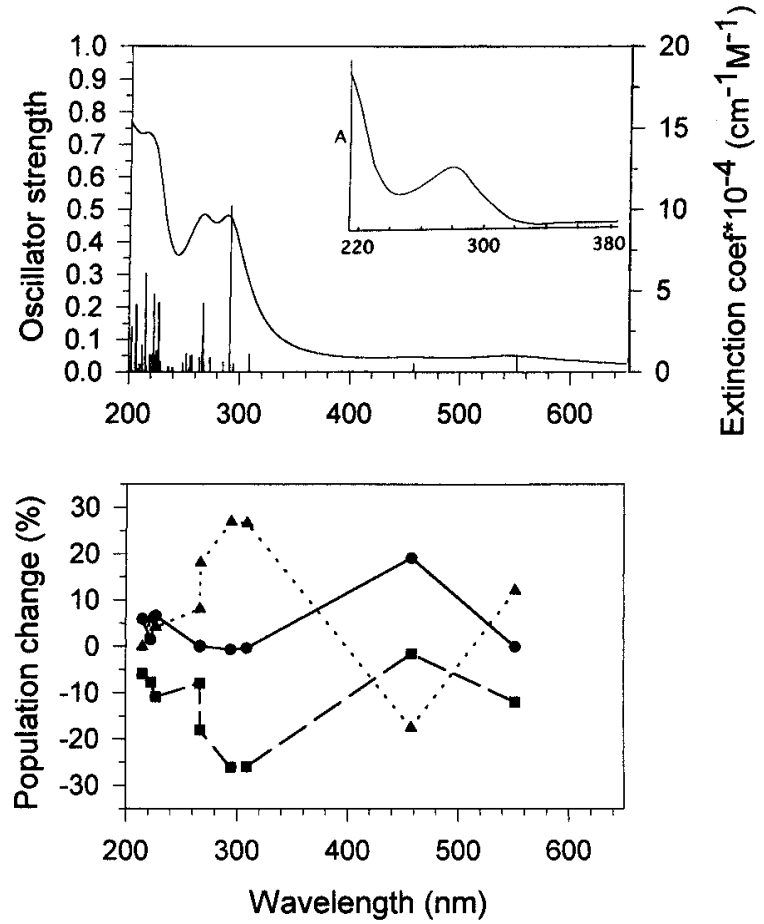

Figure 3. (upper) CNDO oscillator strengths (vertical lines) and simulated spectrum (solid curve) for $\left[\mathrm{Cd}(\mathrm{SPh})_{4}\right]^{2-}([\mathrm{Cd1}])$; inset, experimental absorption spectrum from ref 23. (lower) Changes in electron population from the ground to various excited states. Only dominant transitions are selected. Solid line/circles, Cd; dashed line/ squares, $\mathrm{S}$; dotted line/triangles, $\mathrm{C}$.

do lie higher in energy than bridging ones in both calculations, the energy difference is small. Figures 1 and 2 show the orbital energies from EHT and CNDO, respectively. The two models
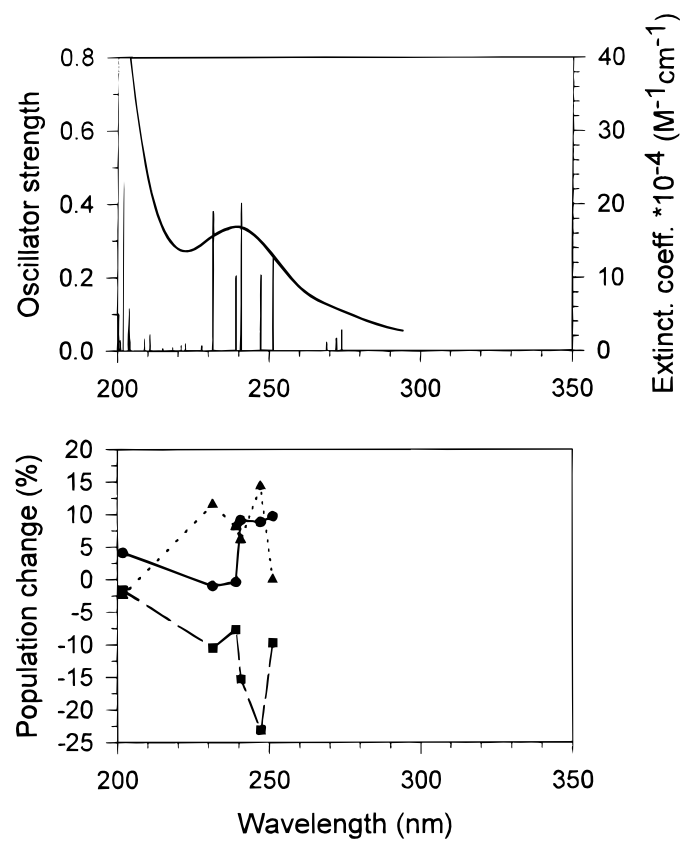

Figure 4. CNDO oscillator strengths, simulated spectrum, and changes in electron population for $\left[\mathrm{Cd}_{2}(\mathrm{SPh})_{6}\right]^{2-}([\mathbf{C d} 2])$. Layout as in Figure 3.
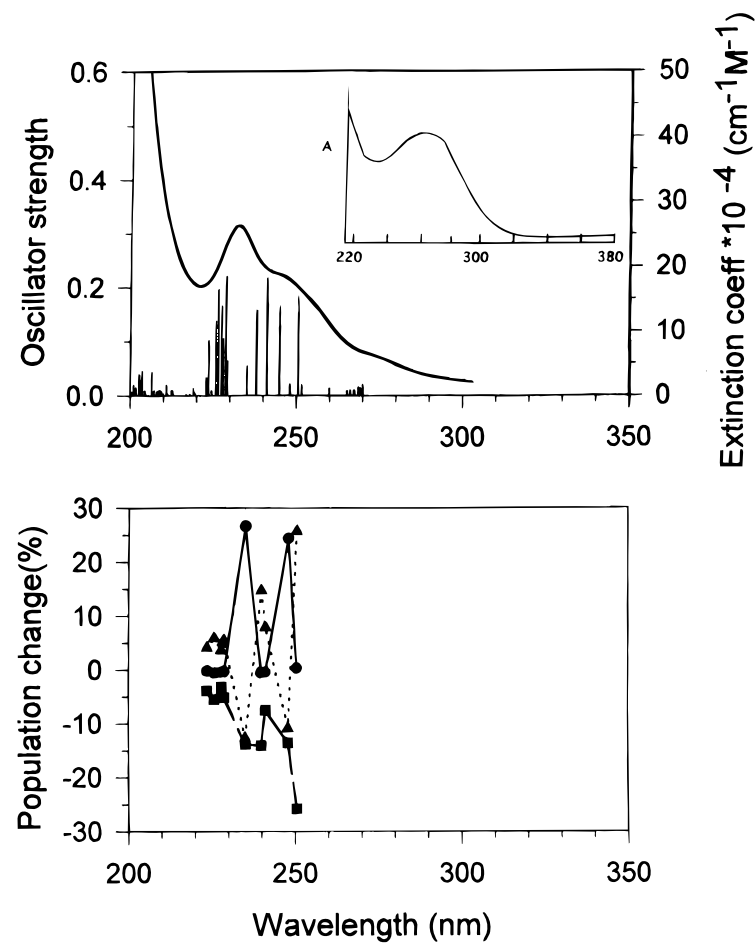

Figure 5. CNDO oscillator strengths, simulated spectrum, and changes in electron population for $\left[\mathrm{Cd}_{4}(\mathrm{SPh})_{10}\right]^{2-}([\mathbf{C d} 4])$. Layout as in Figure 3.

give different results. In Figure 1, EHT results show that orbitals sitting between HOMO and the empty orbitals centered at $\mathrm{Cd} 5 \mathrm{~s}$ orbitals (with energies greater than $-2 \mathrm{eV}$ ) are primarily comprised of antibonding $\pi\left(\pi^{*}\right)$ orbitals localized on thiolates. In other words, $\mathrm{Cd} 5$ s orbitals nearly do not mix with thiolate $\pi^{*}$ orbitals. Thus, from the EHT picture, the lowest energy transitions will be only from sulfur to $\pi^{*}$ orbitals within thiolates; thiolate $\pi$ to $\mathrm{Cd} 5 \mathrm{~s}$ transitions will require much higher energies than the energies for intraligand charge transfer transitions. If we generate an EHT spectrum, the stronger intraligand transitions will lie lower in energy than the weaker thiolate to $\mathrm{Cd}$ transitions. This result is obviously not reason- 
TABLE 1. Calculated and Experimental Spectral Data of the Lowest Energy Transition Bands

\begin{tabular}{|c|c|c|c|c|c|}
\hline \multirow[b]{2}{*}{ compound } & \multicolumn{2}{|c|}{ lowest energy band (nm) } & \multicolumn{2}{|c|}{ extinction coefficient $\left(\mathrm{cm}^{-1} \mathrm{M}^{-1}\right)$} & \multirow{2}{*}{$\frac{\mathrm{fwhm}^{d}}{\Gamma\left(\mathrm{cm}^{-1}\right)}$} \\
\hline & $\mathrm{CNDO} \mathrm{CIS}^{a}$ & expt & $\mathrm{CNDO} \mathrm{CIS}^{a}$ & expt & \\
\hline$\left[\mathrm{Cd}(\mathrm{SPh})_{4}\right]^{2-}$ & $267 / 287$ & $282^{b}$ & $97000 / 96000$ & $20300^{b}$ & 4000 \\
\hline$\left[\mathrm{Cd}_{2}(\mathrm{SPh})_{6}\right]^{2-}$ & 239 & $270^{c}$ & 170000 & $95000^{c}$ & 4000 \\
\hline$\left[\mathrm{Cd}_{4}(\mathrm{SPh})_{10}\right]^{2-}$ & $227 / 239$ & $249 / 275^{b}$ & $264000 / 188000$ & $117400 / 115900^{b}$ & 2500 \\
\hline
\end{tabular}

${ }^{a}$ The band maximum is the local maximum of each simulated curve, and the corresponding extinction coefficient is thus determined. ${ }^{b}$ From ref 27. ${ }^{c}$ From ref $25 .{ }^{d}$ The same $\Gamma$ in eq 5 .

TABLE 2: Transition Energies, ${ }^{a}$ Oscillator Strengths, Changes in Mulliken Population, ${ }^{b}$ and Dipole Moment Changes ${ }^{c}$ of $\left[\mathrm{Cd}(\mathrm{SPh})_{4}\right]^{2-}$

\begin{tabular}{|c|c|c|c|c|c|c|c|c|c|}
\hline \multirow{3}{*}{$\begin{array}{l}\text { transition } \\
\text { energy }(\mathrm{nm})\end{array}$} & \multirow{3}{*}{$\begin{array}{l}\text { oscillator } \\
\text { strength }\end{array}$} & \multicolumn{7}{|c|}{ change in Mulliken population $(\%)$} & \multirow{3}{*}{$\begin{array}{l}\text { dipole moment } \\
\text { change (D) }\end{array}$} \\
\hline & & \multicolumn{3}{|c|}{$\% \mathrm{Cd}$} & \multicolumn{2}{|c|}{$\% \mathrm{~S}$} & \multicolumn{2}{|c|}{$\% \mathrm{C}$} & \\
\hline & & $\mathrm{s}$ & $\mathrm{p}$ & $\mathrm{d}$ & $\mathrm{s}$ & $\mathrm{p}$ & $\mathrm{s}$ & $\mathrm{p}$ & \\
\hline 551.7 & 0.0525 & 0.0 & 0.0 & -0.1 & 0.0 & -12.0 & -1.3 & 13.3 & 1.5 \\
\hline 458.0 & 0.0258 & 18.9 & 0.2 & 0.0 & 1.6 & -3.2 & 0.1 & -17.7 & 0.7 \\
\hline 308.8 & 0.0546 & 0.0 & -0.4 & 0.0 & 0.0 & -26.0 & 0.0 & 26.6 & 2.3 \\
\hline 294.5 & 0.5121 & 0.0 & -0.5 & -0.2 & 0.0 & -26.1 & 0.0 & 26.9 & 5.3 \\
\hline 266.9 & 0.2103 & 0.4 & -0.2 & -0.1 & 0.0 & -18.1 & -0.5 & 18.5 & 14.1 \\
\hline 266.6 & 0.1101 & 0.0 & 0.0 & -0.1 & 0.0 & -8.0 & -0.9 & 9.0 & 21.0 \\
\hline 227.0 & 0.2130 & 7.6 & -0.9 & -0.1 & 0.6 & -11.5 & 0.1 & 4.1 & 2.8 \\
\hline 222.5 & 0.2390 & 2.2 & -0.7 & -0.1 & 0.1 & -7.9 & 0.2 & 6.2 & 4.1 \\
\hline 214.9 & 0.3042 & 6.6 & -0.6 & -0.1 & 0.5 & -6.4 & 0.1 & -0.2 & 2.5 \\
\hline
\end{tabular}

${ }^{a}$ Only dominant transitions are included. ${ }^{b}$ Evalulated by weighted Mulliken population differences of molecular orbitals involved in an electronic transition. Also see text. ${ }^{c}$ The dipole moment change from the ground state to a singly excited state.

TABLE 3: Transition Energies, ${ }^{a}$ Oscillator Strength, Changes in Mulliken Population, ${ }^{b}$ and Dipole Moment Changes ${ }^{c}$ of $\left[\mathrm{Cd}_{2}(\mathrm{SPh})_{6}\right]^{2-}$

\begin{tabular}{|c|c|c|c|c|c|c|c|c|c|}
\hline \multirow{3}{*}{$\begin{array}{l}\text { transition } \\
\text { energy }(\mathrm{nm})\end{array}$} & \multirow{3}{*}{$\begin{array}{l}\text { oscillator } \\
\text { strength }\end{array}$} & \multicolumn{7}{|c|}{ change in Mulliken population (\%) } & \multirow{3}{*}{$\begin{array}{l}\text { dipole moment } \\
\text { change (D) }\end{array}$} \\
\hline & & \multicolumn{3}{|c|}{$\% \mathrm{Cd}$} & \multicolumn{2}{|c|}{$\% \mathrm{~S}$} & \multicolumn{2}{|c|}{$\% \mathrm{C}$} & \\
\hline & & $\mathrm{s}$ & $\mathrm{p}$ & $\mathrm{d}$ & $\mathrm{s}$ & $\mathrm{p}$ & $\mathrm{s}$ & $\mathrm{p}$ & \\
\hline 251.2 & 0.2541 & 10.6 & -0.7 & -0.2 & 0.5 & -10.2 & 0.0 & 0.0 & 0.03 \\
\hline 247.2 & 0.2070 & 10.5 & -1.3 & -0.4 & 0.8 & -23.9 & -0.2 & 14.5 & 0.91 \\
\hline 240.7 & 0.4024 & 10.9 & -1.5 & -0.3 & 0.6 & -15.9 & 0.0 & 6.1 & 1.02 \\
\hline 239.1 & 0.2049 & 0.1 & -0.4 & -0.1 & 0.0 & -7.7 & 0.0 & 8.1 & 0.26 \\
\hline 231.5 & 0.3807 & 0.0 & -0.8 & -0.2 & -0.1 & -10.4 & 0.0 & 11.5 & 0.02 \\
\hline 201.8 & 0.4622 & 4.3 & -0.2 & 0.0 & 0.1 & -1.7 & 0.0 & -2.4 & 0.16 \\
\hline
\end{tabular}

${ }^{a-c}$ As in Table 2.

TABLE 4: Transition Energies, ${ }^{a}$ Oscillator Strengths, Changes in Mulliken Population ${ }^{b}$ and Dipole Moment Changes ${ }^{c}$ of $\left[\mathrm{Cd}_{4}(\mathrm{SPh})_{10}\right]^{2-}$

\begin{tabular}{|c|c|c|c|c|c|c|c|c|c|}
\hline \multirow{3}{*}{$\begin{array}{l}\text { transition } \\
\text { energy (nm) }\end{array}$} & \multirow{3}{*}{$\begin{array}{l}\text { oscillator } \\
\text { strength }\end{array}$} & \multicolumn{7}{|c|}{ change in Mulliken population (\%) } & \multirow{3}{*}{$\begin{array}{l}\text { dipole moment } \\
\text { change (D) }\end{array}$} \\
\hline & & \multicolumn{3}{|c|}{$\% \mathrm{Cd}$} & \multicolumn{2}{|c|}{$\% \mathrm{~S}$} & \multicolumn{2}{|c|}{$\% \mathrm{C}$} & \\
\hline & & $\mathrm{s}$ & $\mathrm{p}$ & $\mathrm{d}$ & $\mathrm{s}$ & $\mathrm{p}$ & $\mathrm{s}$ & $\mathrm{p}$ & \\
\hline 250.5 & 0.1856 & 0.8 & -0.5 & 0.0 & 0.0 & -25.8 & 0.0 & 25.7 & 5.59 \\
\hline 248.0 & 0.0203 & 25.8 & -1.1 & -0.3 & 2.1 & -15.7 & -0.1 & -10.8 & 10.93 \\
\hline 241.1 & 0.2189 & 0.2 & -0.5 & -0.1 & 0.0 & -7.5 & 0.0 & 7.9 & 3.91 \\
\hline 237.9 & 0.1591 & 0.5 & -0.8 & -0.2 & 0.0 & -14.1 & 0.0 & 14.7 & 3.22 \\
\hline 235.1 & 0.0549 & 30.0 & -2.9 & -0.5 & 3.1 & -16.9 & -0.1 & -12.6 & 6.04 \\
\hline 228.7 & 0.2212 & 0.1 & -0.3 & -0.1 & 0.0 & -5.1 & 0.0 & 5.5 & 1.99 \\
\hline 227.9 & 0.1052 & -0.1 & -0.2 & -0.1 & 0.0 & -3.2 & 0.0 & 3.6 & 1.99 \\
\hline 225.8 & 0.1387 & 0.4 & -0.7 & -0.2 & 0.0 & -5.5 & 0.0 & 5.9 & 1.87 \\
\hline 223.6 & 0.1023 & 0.1 & -0.2 & -0.1 & 0.0 & -3.9 & 0.0 & 4.1 & 1.00 \\
\hline
\end{tabular}

${ }^{a-c}$ As in Table 2 .

able: the band shape features of experimental spectra show that the stronger band has higher energy than the weaker one.

On the other hand, from the results of CNDO calculations in Figure 2, the $\pi^{*}$ orbitals on thiolates do mix with $\mathrm{Cd} 5 \mathrm{~s}$ orbitals. As usual with SCF calculations, an artificially large gap between HOMO and LUMO appears. Also note that in Figure 2 the $\mathrm{Cd}$ 5s virtual orbital energies stay about the same from [Cd1] to [Cd4], but the energies of the highest occupied molecular orbitals decrease as the size of the molecule increases. Evidently the electron-electron repulsion considered in the CNDO calculation pushes up the empty thiolate $\pi^{*}$-based molecular orbitals to about the same energy level as the $\mathrm{Cd} 5 \mathrm{~s}$ orbitals.
Although for larger CdS clusters the ratio of the number of stabilizing ligands (e.g., thiolates) versus the number of sulfur atoms is small, a recent study has shown that the ligands are essential to stabilize smaller clusters. ${ }^{3}$ Therefore, the role of ligands cannot be ignored for small clusters.

B. Electronic Absorption Spectra and Changes in Dipole Moment. Since they correct the virtual orbital energies, the CNDO CIS calculations yield lower excitation energies in comparison with orbital energy differences only. The nature of the lowest energy transitions can be understood by performing an analysis of the changes in Mulliken population 
associated with various transitions (Figures 3-5 and Tables $2-4)$.

The CNDO CI results show that the calculated spectra well reproduce the main features of the experimental bands. The experimental UV-vis spectrum for [Cd1] peaks at $282 \mathrm{~nm}$ with a broad band extending from 300 to below $200 \mathrm{~nm}$ (Table 1). ${ }^{27}$ This band was originally assigned to ligand to metal charge transfer (LMCT) transitions. ${ }^{27}$ In the CNDO CI calculated spectrum, the lowest energy band appears in the correct wavelength range $(310-215 \mathrm{~nm})$, but is dominated on the red side by intraligand transitions (see the lower plot in Figure 3). The calculated strong LMCT transitions occur on the blue side of the spectrum (Table 2).

The optical absorption spectrum for [Cd2] has a maximum at $270 \mathrm{~nm}$ and has been previously attributed to both intraligand and thiolate to $\mathrm{Cd}$ transitions (Table 1). ${ }^{25}$ In Figure 4, the stronger transitions within the band centered at $240 \mathrm{~nm}$ clearly include both LMCT and intraligand transitions, but with a greater contribution from the former. Toward the red side of the band, terminal thiolates, and to a lesser extent, bridging thiolates, contribute charge transfer (CT) intensity. The differences in degree of participation are clearly understandable in light of the slightly higher orbital energies for the terminal versus bridging ligands.

The [Cd4] experimental spectrum exhibits a maximum at 249 and an overlapping band at $275 \mathrm{~nm}$, with tails extending from 320 to below $200 \mathrm{~nm} .^{27}$ The combined band has previously been assigned as a ligand to metal charge transfer transition. ${ }^{27}$ As shown by Figure 5, the CNDO CI calculations yield transitions at higher energies than found experimentally. However, the overlapping two-band feature is observed computationally. From Table 4, intraligand excitations clearly must play the major role for both absorption bands, since the LMCT transitions have very small oscillator strengths. Therefore, for [Cd1], [Cd2], and [Cd4], the thiolate $\pi^{*}$ and $\mathrm{Cd} 5 \mathrm{~s}$ orbitals mix to make up the low-lying excited states and the terminal and bridging thiolates contribute mostly to the ground state. The increase in extinction coefficient with increasing molecular size is due to increasing number of atoms in a larger cluster which provides more available states for transitions, rather than greater oscillator strength for each individual transition. The intraligand transitions dominate strongly in the [Cd4] species.

An "anomalous" blue shift with increasing cluster size is observed both experimentally and theoretically (Figures 3-5). This shift is consistent, however, with the systematic decrease in HOMO energy with increasing cluster size (Figure 2). The decreasing HOMO energy effect can be explained by the JahnTeller effect, ${ }^{31}$ which says that the ground state of a molecule is stabilized by undergoing geometry perturbations in order to remove degeneracies in the unperturbed ground state and thus lower the total energy of the molecule. ${ }^{32}$ Consistent with this idea, the $[\mathbf{C d 1}]$ molecule lacks a $T_{d}$ point group symmetry. The bond lengths between $\mathrm{Cd}$ and $\mathrm{S}$ atoms vary from 2.517 to 2.546 $\AA{ }^{33}$ Similarly the [Cd2] molecule has short terminal bond lengths and long bridging bond distances between $\mathrm{Cd}$ and $\mathrm{S}$ atoms. ${ }^{34}$ [Cd4] also experiences geometry distortions: four different terminal $\mathrm{Cd}-\mathrm{S}$ bond lengths (ranging from 2.460 to $2.480 \AA^{35}$ ) and six different bridging $\mathrm{Cd}-\mathrm{S}$ bond lengths (ranging from 2.533 to $2.603 \AA$ ) are observed in the [Cd4] molecule. ${ }^{26}$ Thus $[\mathbf{C d} 4]$ has no symmetry elements $\left(C_{1}\right.$ point group). These geometry distortions in [Cd1], [Cd2], and [Cd4] systematically lower the energy levels of thiolates, and thus blue shifts in the optical spectra are seen.

In contrast to $[\mathbf{C d 1}],[\mathbf{C d} 2]$, and $[\mathbf{C d} 4],\left[\mathrm{S}_{4} \mathrm{Cd}_{10}(\mathrm{SPh})_{16}\right]^{4-}$ $([\mathbf{C d 1 0}])^{36}$ does possess several sets of $\mathrm{Cd}$ and $\mathrm{S}$ atoms that
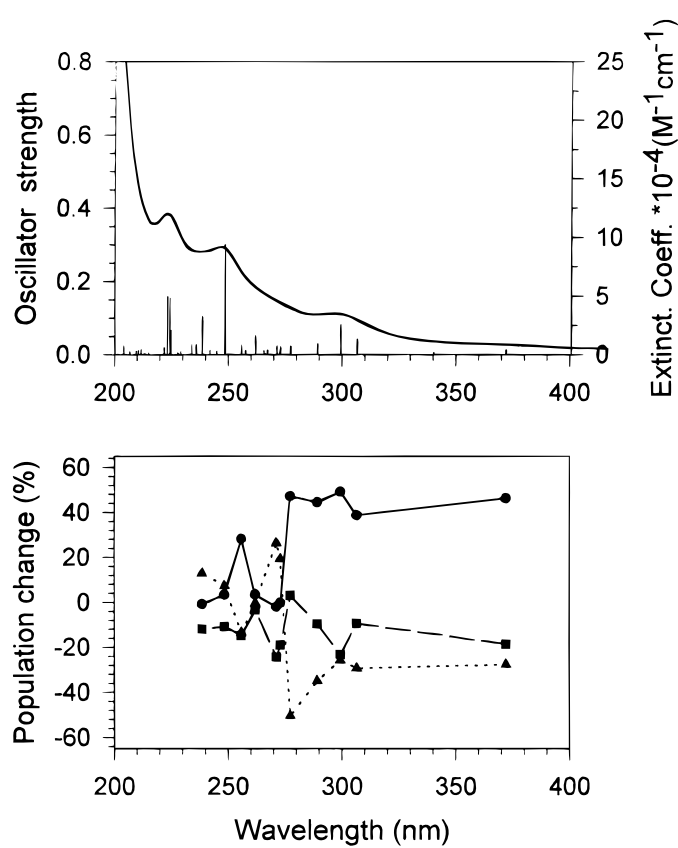

Figure 6. CNDO oscillator strengths, simulated spectrum, and changes in electron population for $\left[\mathrm{Cd}_{2}(\mathrm{SPh})_{5}\right]^{-}$. Layout also as in Figure 3. Note that more transitions with small oscillator strength appear at the red side of the spectrum and they have a character of $\mathrm{S}$ and $\pi$ to $\mathrm{Cd}$ charge transfer. See text also.
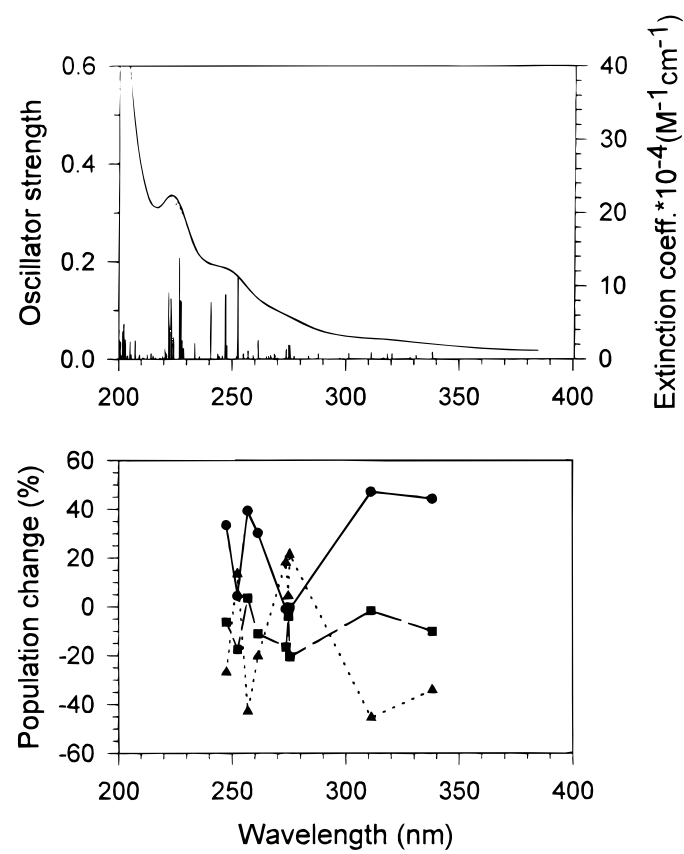

Figure 7. CNDO oscillator strengths, simulated spectrum, and changes in electron population for $\left[\mathrm{Cd}_{4}(\mathrm{SPh})_{9}\right]^{-}$. Layout as in Figure 3. Note that transitions with small oscillator strength at the red side of the spectrum correspond to the charge transfer from $\mathrm{S}$ and $\pi$ to $\mathrm{Cd}$. See text also.

are crystallographically equivalent to other atoms in the same molecule. ${ }^{37}$ These equivalent sets, originating from the crystal symmetry, bring together discrete levels to yield bandlike states; the bandwidths, which are determined by the number of participating atoms or moieties, play a major role in determining the energies of transitions from the "valence band" to the "conduction band".

For bulk materials, surface relaxation and surface reconstruction are the two dominant factors defining whether surface states are significant. ${ }^{38}$ As the size of a material decreases, the ratio of surface atoms to "core" atoms obviously increases. In the 
TABLE 5: Transition Energies, ${ }^{a}$ Oscillator Strengths, Changes in Mulliken Population, ${ }^{b}$ and Dipole Moment Changes ${ }^{c}$ of $\left[\mathrm{Cd}_{2}(\mathrm{SPh})_{5}\right]^{-}$

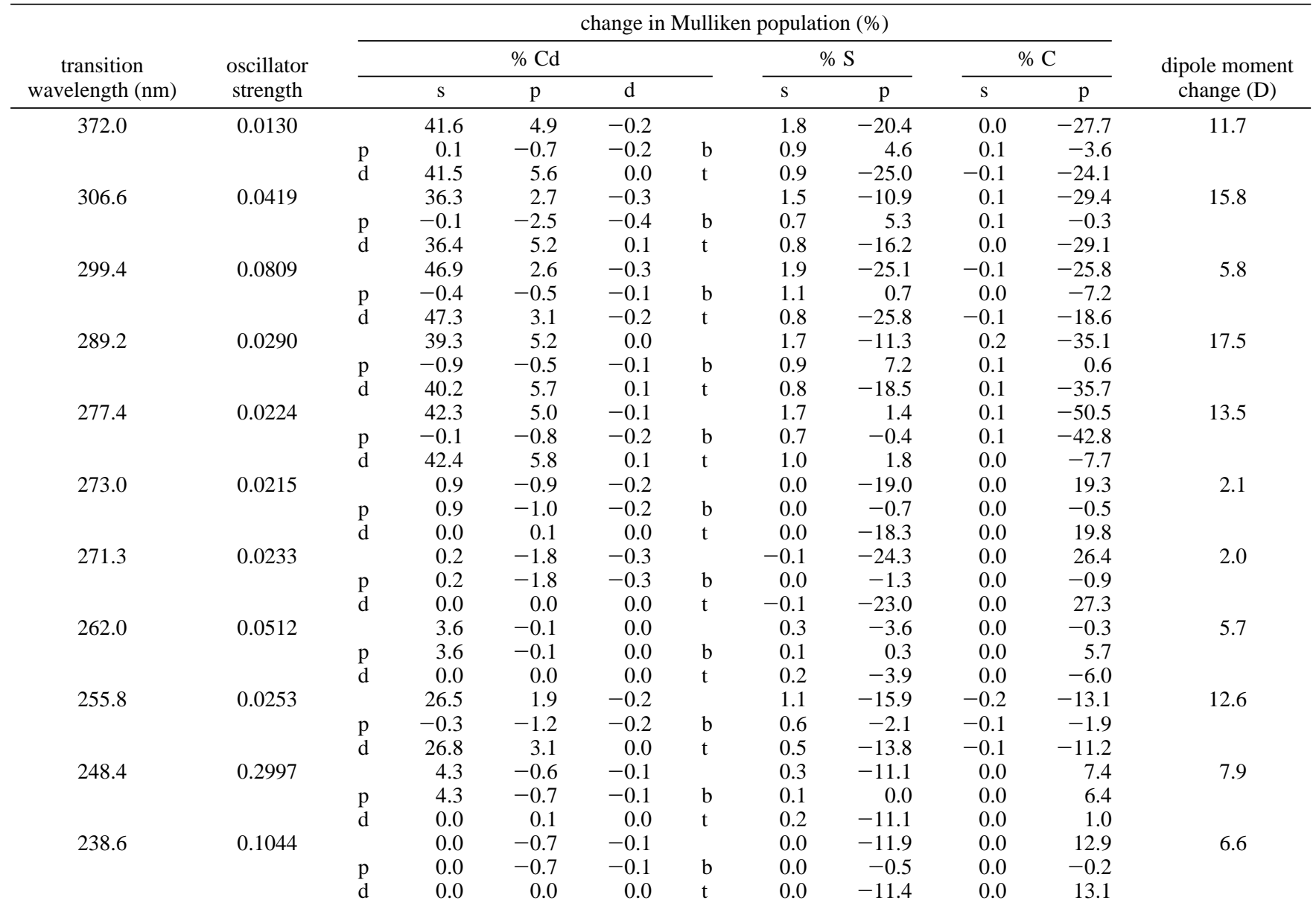

${ }^{a-c}$ As in Table 2. p, d, b, t denotes Cd with complete coordination, Cd with incomplete coordination, bridging ligand, terminal ligand.

limit of very small particle sizes (i.e. clusters), therefore, surface states and geometry distortions may well dominate the electronic structure.

The question of how electron density is redistributed upon optical excitation clearly is related to the issue of how the dipole moment is changed upon conversion of the clusters from ground state to an excited state. For example, in Table 2, transitions for [Cd1] at 294.5 and $266.9 \mathrm{~nm}$ can both be characterized as intraligand charge transfer. However, their dipole moment changes differ $(5.3 \mathrm{~d}$ vs $14.1 \mathrm{D})$. Further study on the population changes shows that the $294.5 \mathrm{~nm}$ transition mainly occurs on one ligand, while the $266.9 \mathrm{~nm}$ transition involves charge transfer from one ligand to another, thus the larger dipole moment change for the latter. On the other hand, the small net dipole moment change at $227 \mathrm{~nm}$ (Table 2) reflects simultaneous charge transfer from sulfur to both cadmium and benzene. This results in partial cancellation of changes in dipole moment. Small dipole moment changes are also encountered for transitions involving [Cd2] (Table 3). Here, however, an additional factor may come into play. The cadmium atoms in [Cd1] and [Cd4] molecules do not have a particular point group symmetry associated with them. The [Cd2] molecule, on the other hand, possesses a reflection center $(i)$. This center inhibits electron localization. Since the hole is delocalized, localization of an excited electron causes a significant dipole moment change, while delocalization results in a small change in dipole moment.

C. Effects of Defect Sites on Optical Spectra. Experimental studies on surface states and exciton traps of quantumconfined particles suggest that surface electronic levels mix with interior levels. ${ }^{4 \mathrm{a}, 5 \mathrm{~b}}$ Surface states can arise either from differ- ences of redox properties of surface moieties from the core, which implies delocalization of surface states, or from incomplete coverage of the particle surface, which may imply localization of surface states. ${ }^{39-45}$ Here we try to mimic the effects of incomplete surface capping by removing one terminal thiolate from $[\mathbf{C d 2}]$ and $[\mathbf{C d 4}]$. CNDO results show that a dangling bond on the $\mathrm{Cd}$ atom creates a distinct low-lying $\mathrm{Cd}$ 5 s empty orbital, which acts as an electron acceptor/trap upon an electronic excitation. In Figures 6 and 7, new excitations from both terminal and bridging thiolates to the defect cadmium generate new transitions with small oscillator strengths at the red end of a spectrum (cf. Figures 4 and 5). Although terminal thiolates play a major role as electron donors, there again are no significant energy differences between terminal and bridging thiolates. In addition, as shown in the lower plots in both figures, these transitions have a strong ligand to metal charge transfer character. As one might expect, a significant dipole moment change associated with each "LMCT" excitation is obvious (Tables 5, 6).

Computational limitations preclude similar calculations on larger clusters such as $\left[\mathrm{S}_{4} \mathrm{Cd}_{10}(\mathrm{SPh})_{16}\right]^{2-},{ }^{36}\left[\mathrm{~S}_{13} \mathrm{Cd}_{20}(\mathrm{SPh})_{22}\right]^{2-}, 46$ and $\mathrm{S}_{14} \mathrm{Cd}_{32}(\mathrm{SPh})_{36} ;{ }^{47}$ however, the long red tails and the corresponding significant dipole moment changes found for the defect structures (but absent in Figures 2-4) suggest that if exciton trapping is due to incomplete capping on the surface, then exciton localization and a large dipole moment change (perhaps observable by Stark spectroscopy) should generally be expected. We note that the degree of dipolar character of excited states for very large clusters is still controversial experimentally. 5,6 On the other hand, the small oscillator 
TABLE 6: Transition Energies, ${ }^{a}$ Oscillator Strengths, Changes in Mulliken Population, ${ }^{b}$ and Dipole Moment Changes $^{c}$ of $\left[\mathrm{Cd}_{4}(\mathrm{SPh})_{9}\right]^{-}$

\begin{tabular}{|c|c|c|c|c|c|c|c|c|c|c|c|}
\hline \multirow{3}{*}{$\begin{array}{c}\text { transition } \\
\text { wavelength }(\mathrm{nm})\end{array}$} & \multirow{3}{*}{$\begin{array}{c}\text { oscillator } \\
\text { strength }\end{array}$} & \multicolumn{9}{|c|}{ change in Mulliken population (\%) } & \multirow{3}{*}{$\begin{array}{l}\text { dipole moment } \\
\text { change (D) }\end{array}$} \\
\hline & & \multicolumn{4}{|c|}{$\% \mathrm{Cd}$} & & \multicolumn{2}{|c|}{$\% \mathrm{~S}$} & \multicolumn{2}{|c|}{$\% \mathrm{C}$} & \\
\hline & & & $\mathrm{s}$ & $\mathrm{p}$ & $\mathrm{d}$ & & $\mathrm{s}$ & $\mathrm{p}$ & $\mathrm{s}$ & $\mathrm{p}$ & \\
\hline \multirow[t]{3}{*}{338.3} & 0.0143 & & 39.1 & 5.1 & 0.0 & & 2.0 & -12.1 & 0.1 & -34.2 & 22.9 \\
\hline & & $\mathrm{p}$ & 0.0 & -0.1 & 0.0 & $\mathrm{~b}$ & 2.0 & 10.3 & 0.1 & -0.9 & \\
\hline & & $\mathrm{d}$ & 39.1 & 5.2 & 0.0 & $\mathrm{t}$ & 0.0 & -22.4 & 0.0 & -33.3 & \\
\hline \multirow[t]{3}{*}{311.3} & 0.0134 & & 42.4 & 4.8 & -0.1 & & 2.2 & -3.9 & 0.0 & -45.4 & 21.8 \\
\hline & & $\mathrm{p}$ & 0.0 & -0.8 & -0.2 & $\mathrm{~b}$ & 2.2 & -2.5 & 0.0 & -44.2 & \\
\hline & & $\mathrm{d}$ & 42.4 & 5.6 & 0.1 & $\mathrm{t}$ & 0.0 & -1.4 & 0.0 & -1.2 & \\
\hline \multirow[t]{3}{*}{275.5} & 0.0274 & & 0.0 & -0.5 & -0.1 & & 0.0 & -20.6 & 0.0 & 21.4 & 15.8 \\
\hline & & $\mathrm{p}$ & 0.0 & -0.5 & -0.1 & $\mathrm{~b}$ & 0.0 & -0.7 & 0.0 & 3.3 & \\
\hline & & $\mathrm{d}$ & 0.0 & 0.0 & 0.0 & $\mathrm{t}$ & 0.0 & -19.9 & 0.0 & 18.1 & \\
\hline \multirow[t]{3}{*}{274.9} & 0.0275 & & 0.0 & -0.3 & 0.0 & & 0.0 & -3.9 & 0.0 & 4.3 & 3.9 \\
\hline & & $\mathrm{p}$ & 0.0 & -0.3 & 0.0 & $\mathrm{~b}$ & 0.0 & -0.7 & 0.0 & 3.4 & \\
\hline & & $\mathrm{d}$ & 0.0 & 0.0 & 0.0 & $\mathrm{t}$ & 0.0 & -3.2 & 0.0 & 0.9 & \\
\hline \multirow[t]{3}{*}{273.8} & 0.0195 & & -0.3 & -0.9 & -0.2 & & 0.0 & -16.6 & 0.0 & 18.1 & 1.8 \\
\hline & & $\mathrm{p}$ & -0.3 & -0.9 & -0.2 & $\mathrm{~b}$ & 0.0 & -1.6 & 0.0 & 3.4 & \\
\hline & & $\mathrm{d}$ & 0.0 & 0.0 & 0.0 & $\mathrm{t}$ & 0.0 & -15.0 & 0.0 & 14.7 & \\
\hline \multirow[t]{3}{*}{261.5} & 0.0383 & & 27.4 & 2.9 & -0.2 & & 1.4 & -11.3 & -0.1 & -20.3 & 19.9 \\
\hline & & $\mathrm{p}$ & -0.4 & -0.6 & -0.2 & $\mathrm{~b}$ & 1.4 & 4.7 & 0.0 & -14.8 & \\
\hline & & $\mathrm{d}$ & 27.8 & 3.5 & 0.0 & $\mathrm{t}$ & 0.0 & -16.0 & -0.1 & -5.5 & \\
\hline \multirow[t]{3}{*}{257.0} & 0.0163 & & 35.1 & 4.3 & -0.1 & & 1.7 & 1.8 & 0.0 & -42.9 & 14.9 \\
\hline & & $\mathrm{p}$ & 0.0 & -0.3 & -0.1 & $b$ & 1.7 & 4.5 & 0.0 & -30.4 & \\
\hline & & $\mathrm{d}$ & 35.1 & 4.6 & 0.0 & $\mathrm{t}$ & 0.0 & -2.7 & 0.0 & -12.5 & \\
\hline \multirow[t]{3}{*}{252.5} & 0.1708 & & 5.9 & -1.3 & -0.2 & & 0.6 & -18.2 & 0.0 & 13.5 & 6.5 \\
\hline & & $\mathrm{p}$ & 5.9 & -1.3 & -0.2 & $\mathrm{~b}$ & 0.6 & 0.1 & 0.0 & 8.8 & \\
\hline & & $\mathrm{d}$ & 0.0 & 0.0 & 0.0 & $\mathrm{t}$ & 0.0 & -18.3 & 0.0 & 4.7 & \\
\hline \multirow[t]{3}{*}{247.6} & 0.0272 & & 30.5 & 2.9 & -0.3 & & 1.5 & -7.8 & -0.1 & -26.7 & 15.7 \\
\hline & & $\mathrm{p}$ & 0.0 & -1.1 & -0.3 & $\mathrm{~b}$ & 1.5 & -6.6 & -0.1 & -24.7 & \\
\hline & & $\mathrm{d}$ & 30.5 & 4.0 & 0.0 & $\mathrm{t}$ & 0.0 & -1.2 & 0.0 & -2.0 & \\
\hline
\end{tabular}
ligand.

strengths associated here with large $\Delta \mu$ transitions clearly suggest that discrete strong optical transitions from the delocalized ground state to such trapped states cannot occur, at least if the surface trap states are ascribed to incomplete coordination of the surface. Due to the poor overlap between the ground state and the Cd-localized trap state, it is unlikely that light can be emitted efficiently (i.e., both rapidly and with high quantum efficiency) upon relaxation from the excited $\mathrm{Cd}$ trap state. This is supported by recent experimental studies. ${ }^{48}$ Nevertheless, basic questions of the nature of surface states and correlation of an exciton trap with the surface redox properties, incomplete coverage on the surface, and even the packing faults of clusters are still uncertain and require more study.

D. Solvent Effect. By using the SCRF model to examine the effect of solvation of clusters by acetonitrile, we see shifts in optical transition energy ranging from several $\mathrm{cm}^{-1}$ to (at most) ca. $400 \mathrm{~cm}^{-1}$. Therefore the simulated spectra suffer no significant change upon inclusion of solvation. According to the SCRF model, the shift in energy due to solvation will be proportional to the square of the dipole moment and inversely proportional to the cube of the solute radius, $\Delta \mu^{2} / a^{3}$. Since even small clusters have rather large radii by molecular standards (5.4, 6.3, and 7.4 А̊, respectively for [Cd1], [Cd2], and [Cd4]), even a change in dipole moment as great as $10 \mathrm{D}$ will decrease the transition energy by only a few hundred wavenumbers. The same situation is observed in calculations on defect molecules. The SCRF model thus predicts only small absorption energy shifts. However, it is not clear that the SCRF model is adequate for these clusters. Of particular concern is the assumption of a strictly spherical solvent cavity with no specific local interaction between solute and solvent. It neglects specific effects such as those brought about by solvent coordination at the trap state. Experimental studies show that coordinating solvents can stabilize nanocrystallites and increase solubility; ${ }^{49}$ both observa-

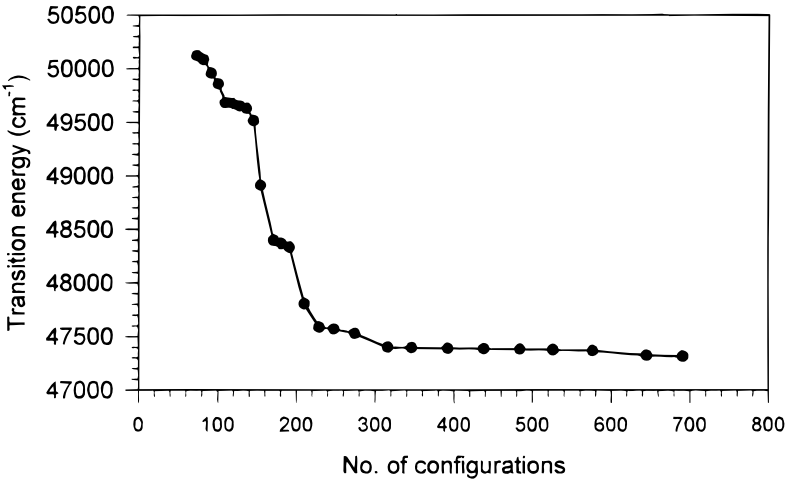

Figure 8. Number of singly excited configurations versus transition energy for [Cd1]. As more than 300 configurations are included in the CI calculation, the transition energy curve becomes a flat line.

tions suggest roles for local interactions between particle and solvent. Furthermore, small CdS clusters have a decidedly nonspherical shape..$^{36,46,47,49}$ At this early stage, even an experimental consensus on solvent effects is still lacking. $3,46,50$

\section{Conclusions}

The simulated spectra in the CNDO calculations well reproduce the main features of experiments. The lowest energy band is made up of transitions with both LMCT (thiolates to $\mathrm{Cd} 5 \mathrm{~s}$ ) and intraligand charge transfer character. The blue shift with increasing cluster size, observed both experimentally and theoretically, can be explained by the Jahn-Teller effect which emphasizes the importance of geometric distortions to the electronic structure of the cluster. Also accompanying these distortions are reduction in symmetry, resulting in diminution of orbital degeneracy and enhanced localization. If the electron is localized on one site (either on a single $\mathrm{Cd}$ atom or a thiolate) 


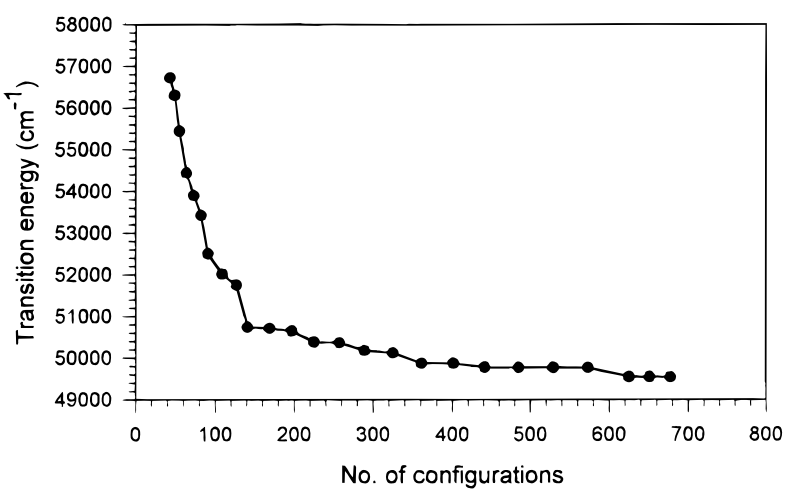

Figure 9. Number of singly excited configurations versus transition energy for [Cd2]. The flat region starts where the number of configurations is greater than 350 .

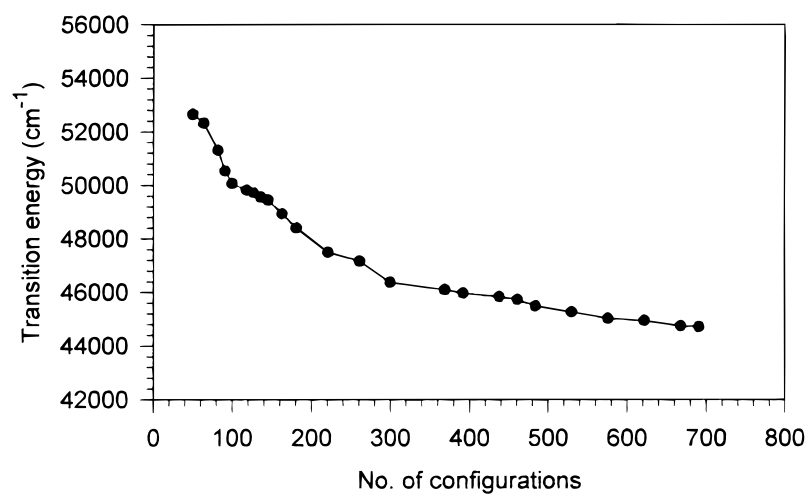

Figure 10. Number of singly excited configurations versus transition energy for [Cd4].

in an excited state, a significant change in dipole moment from the ground to the excited state results. However, if a molecule possesses an $i$ symmetry center, vanishing changes in dipole moment are expected.

Removal of one terminal ligand creates a defect site on a $\mathrm{Cd}$ atom. This, in turn, yields several weak transitions associated with excitations from thiolate ligands to the incompletely capped $\mathrm{Cd}$. These transitions collectively appear as a long tail on the red side of the spectrum. Significant changes in dipole moment, attributed to localization of an excited electron, are associated with these transitions. However, the small oscillator strengths associated with these transitions indicate poor overlap between the ground and the trap states, which suggests that it is unlikely that the $\mathrm{Cd}$ atoms with incomplete capping can serve as both surface trap states and efficient light-emitting states.

Solvent effects have also been examined by using the SCRF model. Due to the large molecular radii, no significant changes in simulated spectra are observed.

Acknowledgment. We thank the Chemistry Division of the Office of Naval Research and the Materials Research Center of Northwestern University (contract DMR-9120521) for funding this research. H.J.L. thanks Dr. I. D. L. Albert for valuable help in handling ZINDO and useful discussions.

\section{Appendix A}

To assure that the CI calculation is converged as a function of the number of excitations, plots of transition energy versus number of configurations are made for three transitions chosen from the blue side of each [Cd1], [Cd2], and [Cd4] spectrum.

From Figures 8 and 9, the number of configurations included in CI calculations (691 and 677 for [Cd1] and [Cd2], respec- tively) place the calculations in the flat regions of the curves, indicating that convergence has occurred.

In Figure 10, although the number of atomic orbitals increases rapidly with increasing cluster size, the transition energy itself becomes stable if the number of configurations is greater than 650 .

\section{Appendix B}

The default ionization potentials $\left(\mathrm{U}_{\mu \mu}\right)$, bonding parameters $\left(\beta_{\mathrm{A}}\right)$, and one-center two-electron Coulomb integrals $\left(\gamma_{\mathrm{AA}}\right)$ for $\mathrm{H}, \mathrm{C}$, and $\mathrm{S}$ are taken as ${ }^{19}$

$\begin{array}{llrcc} & U_{\mathrm{ss}}(\mathrm{eV}) & U_{\mathrm{pp}}(\mathrm{eV}) & \beta_{\mathrm{A}}(\mathrm{eV}) & \gamma_{\mathrm{AA}^{a}} \\ \mathrm{H} & -13.06 & -3.23 & -12 & 12.85 \\ \mathrm{C} & -19.65 & -11.13 & -17 & 11.11 \\ \mathrm{~S} & -22.76 & -12.08 & -35 & 10.09\end{array}$

${ }^{a} \gamma_{\mathrm{ss}}=\gamma_{\mathrm{pp}}=\gamma_{\mathrm{sp}}$

\section{References and Notes}

(1) For recent reviews, see: (a) Bawendi, M. G.; Steigerwald, M. L.; Brus, L. E. Annu. Rev. Phys. Chem. 1990, 41, 477. (b) Wang, Y.; Herron, N. J. Phys. Chem. 1991, 95, 525. (c) Brus, L. E. Appl. Phys. 1991, A53, 465. (d) Weller, H. Angew. Chem., Int. Ed. Engl. 1993, 32, 41.

(2) (a) Murray, C. B.; Norris, D. J.; Bawendi, M. G. J. Am. Chem. Soc. 1993, 115, 8706. (b) Norris, D. J.; Nirmal, M.; Murray, C. B.; Sacra, A.; Bawendi, M. G. Z. Phys. D 1993, 26, 355. (c) Nirmal, M.; Murray, C. B.; Norris, D. J.; Bawendi, M. G. Z. Phys. D 1993, 26, 361. (d) Ekimov, A. I.; Hache, F.; Schanne-Klein, M. C.; Ricard, D.; Flytzanis, C. J. Opt. Soc. Am. B 1993, 10, 100. (e) Hoheisel, W.; Colvin, V. L.; Johnson, C. S.; Alivisatos, A. P. J. Chem. Phys. 1994, 101, 8455.

(3) Vossmeyer, T.; Katsikas, L.; Giersig, M.; Popovic, I. G.; Diesner, K.; Chemseddine, A.; Eychmuller, A.; Weller, H. J. Phys. Chem. 1994, 98, 7665.

(4) (a) Bawendi, M. G.; Carroll, P. J.; Wilson, W. L.; Brus, L. E. J. Chem. Phys. 1992, 96, 946. (b) Torimoto, T.; Uchida, H.; Sakata, T.; Mori, H.; Yoneyama, H. J. Am. Chem. Soc. 1993, 115, 1874. (c) Becerra, L. R.; Murray, C. B.; Grifin, R. G.; Bawendi, M. G. J. Chem. Phys. 1994, 100, 3297.

(5) (a) Colvin, V. L.; Alivisatos, A. P. J. Chem. Phys. 1992, 97, 730. (b) Colvin, V. L.; Cunningham, K. L.; Alivisatos, A. P. J. Chem. Phys. 1994, 101, 7122 .

(6) Sacra, A.; Norris, D. J.; Murray, C. B.; Bawendi, M. G. J. Chem. Phys. 1995, 103, 5236.

(7) (a) Brus, L. E. J. Chem. Phys. 1983, 79, 5566. (b) J. Chem. Phys. 1984, 80,4403 .

(8) Efros, Al. L.; Efros, A. L. Sov. Phys. Semicond. 1982, 16, 772.

(9) Nomura, S.; Kobayashi, T. J. Appl. Phys. 1994, 75, 382.

(10) (a) Lippens, P. E.; Lannoo, M. Phys. Rev. B 1989, 39, 10935; (b) Phys. Rev. B 1990, 41, 6079; (c) Mater Sci. Eng. 1991, 139, 485

(11) (a) Hill, N. A.; Whaley, K. B. J. Chem. Phys. 1993, 99, 3707. (b)

Hill, N. A.; Whaley, K. B. J. Chem. Phys. 1994, 100, 2831.

(12) (a) Rama Krishna, M. V.; Friesner, R. A. Phys. Rev. Lett. 1991, 67, 629; (b) J. Chem. Phys. 1991, 95, 8309; (c) Isr. J. Chem. 1993, 33, 3.

(13) Zorman, B.; Ramakrishna, M. V.; Friesner, R. A. J. Phys. Chem. 1995, 99, 7649 .

(14) For a recent review, see: Ratner, M. A. In Structure and Dynamics of Atoms and Molecules: Conceptual Trends; Calais, J. L., Kryachko, E. S., Eds.; Kluwer Academic Publishers: Dordrecht, 1995; p 183.

(15) Hoffmann, R. J. Chem. Phys. 1963, 39, 1397.

(16) (a) Pople, J. A.; Segal, G. A. J. Chem. Phys. 1965, 43, S136. (b) Pople, J. A.; Beveridge, D. L. Approximate Molecular Orbital Theory; McGraw Hill: New York, 1970.

(17) Wolfsberg, M.; Helmholz, L. J. Chem. Phys. 1952, 20, 837.

(18) (a) Freund, H.-J.; Hohlneicher, G. Theor. Chim. Acta 1979, 51, 145. (b) Freund, H.-J.; Dick, B.; Hohlneicher, G. Theor. Chim. Acta 1980, 57, 181.

(19) Zerner, M. C., and co-workers, Quantum Theory Project, University of Florida, Gainesville, Florida.

(20) Clark, D. W.; Hush, N. S.; Yandle, J. R. J. Chem. Phys. 1972, 57, 3503.

(21) Mataga, N.; Nishimoto, K. Z. Phys. Chem. 1957, 13, 140.

(22) $K_{\sigma}^{\mathrm{s}}=1, K_{\sigma}^{\mathrm{p}}=1.267, K_{\sigma}^{\mathrm{d}}=1, K_{\pi}^{\mathrm{p}}=0.585, K_{\pi}^{\mathrm{d}}=1$.

(23) Anderson, W. P.; Cundari, T. R.; Zerner, M. C. Int. J. Quantum Chem. 1991, 39, 31

(24) Swenson, D.; Baeiger, N. C.; Coucouvanis, D. J. Am. Chem. Soc. 1978, $100,1932$.

(25) Abrahams, I. L.; Garner, C. D. J. Chem. Soc., Dalton Trans. 1987, 1577 . 
(26) Hagen, K. S.; Holm, R. H. Inorg. Chem. 1983, 22, 3171.

(27) Turk, T.; Resch, U.; Fox, M. A.; Vogler, A. J. Phys. Chem. 1992 96,3818

(28) For example, see: Lever, A. B. P. Inorganic Electronic Spectroscopy; Elsevier: New York, 1984), p 162. Gilbert, A.; Baggott, J. Essentials of Molecular Photochemistry; CRC Press: Boca Raton, 1991, pp 84-86.

(29) $k=\left(4 \epsilon_{0} m_{\mathrm{e}} c^{2} \ln 10\right) / N_{\mathrm{A}} e^{2}=4.33 \times 10^{-9} \mathrm{~cm}^{-2}$ M. $\epsilon_{0}$, permittivity of vacuum; $m_{\mathrm{e}}$, electron rest mass; $c$, speed of light; $N_{\mathrm{A}}$, Avogadro constant; $e$, proton charge.

(30) Karelson, M. M.; Zerner, M. C. J. Phys. Chem. 1992, 96, 6949.

(31) Jahn, H. A.; Teller, E. Proc. R. Soc. 1937, A161, 220.

(32) Albright, T. A.; Burdett, J. K.; Whangbo, M.-H. Orbital Interactions in Chemistry; John Wiley \& Sons: New York, 1985; pp 91-100.

(33) Four $\mathrm{Cd}-\mathrm{S}$ bond lengths are $2.517,2.535,2.540$, and $2.546 \AA$ from ref 24 .

(34) The two different terminal $\mathrm{Cd}-\mathrm{S}$ bond lengths of [Cd2] are 2.477 and $2.478 \AA$. The bridging $\mathrm{Cd}-\mathrm{S}$ bond distance is $2.611 \AA$ (ref 25).

(35) They are $2.463,2.460,2.465$, and $2.480 \AA$ (ref 26).

(36) Dance, I. G.; Choy, A.; Scudder, M. L. J. Am. Chem. Soc. 1984, 106,6285 .

(37) Among $10 \mathrm{Cd}$ atoms in the $[\mathbf{C d 1 0}]$ molecule, for example, there are three sets of $\mathrm{Cd}$ atoms. Four terminal ligands are crystallographically equivalent, but the other $16 \mathrm{~S}$ atoms are divided into four sets. Therefore [Cd10] does not possess a point group symmetry. See ref 36.

(38) Wimmer, E.; Freeman, A. J. Unpublished.
(39) Rossetti, R.; Brus, L. E. J. Phys. Chem. 1982, 86, 4470.

(40) O’Neil, M.; Marohn, J.; McLendon, G. Chem. Phys. Lett. 1990 168, 208.

(41) Kaschke, M.; Ernsting, N. P.; Muller, U.; Weller, H. Chem. Phys. Lett. 1990, 168, 543.

(42) Hache, F.; Klein, M. C.; Ricard, D.; Flytzanis, C. J. Opt. Soc. Am. B 1991, 8, 1802.

(43) Bawendi, M. G.; Carrol, P. J.; Wilson, W. L.; Brus, L. E. J. Chem. Phys. 1992, 96, 946.

(44) Nirmal, M.; Murray, C. B.; Bawendi, M. G. Phys. Rev. B 1994 $50,2293$.

(45) Bowers, C. R.; Pietrass, T.; Barash, E.; Pines, A.; Grubbs, R. K.; Alivisatos, A. P. J. Phys. Chem. 1994, 98, 9440.

(46) (a) Herron, N.; Suna, A.; Wang, Y. J. Chem. Soc., Dalton Trans. 1992, 2329. (b) Wang, Y.; Harmer, M.; Herron, N. Isr. J. Chem. 1993, 33,31 .

(47) Herron, N.; Calabrese, J. C.; Farneth, W. E.; Wang, Y. Science 1993, 259, 1426.

(48) Norris, D. J.; Bawendi, M. G. J. Chem. Phys. 1995, 103, 5260.

(49) For example, use of $\mathrm{Bu}_{3} \mathrm{P} / \mathrm{Bu}_{3} \mathrm{PO}$ in ref 41 and TOP/TOPO in the paper by Murray et al., ref 20.

(50) Vossmeyer, T.; Reck, G.; Katsikas, L.; Haupt, E. T. K.; Schulz, B.; Weller, H. Science 1995, 267, 1476.

JP960426T 